International Journal of Current Microbiology and Applied Sciences

ISSN: 2319-7706 Volume 10 Number 09 (2021)

Journal homepage: http://www.ijcmas.com

\title{
Conjoint Analysis for Selecting the Ingredients Levels of Fortified Beverage
}

\author{
R. Navarasam ${ }^{\text {* }}$, Ayyavoo Preamnath Manoharan', V. Appa Rao ${ }^{3}$, \\ T. R. Pugazhenthi ${ }^{4}$ and A. Serma Saravana Pandian ${ }^{5}$
}

\author{
${ }^{1}$ Department of Food Technology, ${ }^{2}$ Department of Food Process Engineering, \\ ${ }^{3}$ Department of Food Sciences, College of Food and Dairy Technology (TANUVAS), \\ Koduvalli, Chennai-600 052, India \\ ${ }^{4}$ Department of Livestock Products Technology (Dairy Science), \\ ${ }^{5}$ Department of AH Economics, Madras Veterinary College, Vepery (TANUVAS), Vepery, \\ Chennai- 600 007, India \\ *Corresponding author
}

Keywords

Conjoint Analysis,

Consumer

Preference,

Fortified Beverage,

Optimization of

Ingredients Levels

Article Info

Accepted:

10 August 2021

Available Online:

10 September 2021

\section{A B S T R A C T}

This research paper concentrated on the "Conjoint Analysis for Selecting the Ingredients Levels of Fortified Beverage". Conjoint analysis is a multivariate technique used specifically to understand how consumers develop preferences for products or services and to formulate predictions about ingredients levels towards product concepts and it is also called as trade-off analysis. The fortified beverage was prepared with various levels of ingredients such as Carrot $(5 \%, 10 \%$ and $15 \%)$, Moringa $(5 \%, 10 \%$ and $15 \%)$, Mushroom (3\%,6\% and 9\%), Dates $(1 \%, 2 \%$ and $3 \%)$ and Seaweed $(1 \%, 2 \%$ and $3 \%)$. Since, this large number of combinations led to nonresponsible of consumers and improper results may be obtained. Hence, the conjoint analysis for selecting the best ingredient levels of ideal fortified beverage is based on the utility estimation and relative importance of attributes and was found that it should have the following attributes combination: Carrot -15 per cent, Mushroom - 6 Per cent, Moringa - 5 per cent, Dates -2 per cent and Sea Weed -1 per cent.

\section{Introduction}

In today's market, innumerable new products appear. Among these, a beverage is the easiest new fruit products introduction. Fruit beverages are able to provide more kinds of nutrient flavour and other physiological benefits with a greater margin of safety in a 
drink with lower cost. Thus as an initial attempt, beverages were chosen in the study. Synthetic drinks which are more popular commercially are not so healthy or nutritive compared to natural ones. Hence, if natural drinks could substitute to synthetic drinks, it would offer numerous health benefits to consumers as well as farmers. However, the cost economics for natural drinks could not feasible as that to synthetic drinks.

Due to the increase in demands for natural and organic products, fruit juice and other fruitbased beverages has great scope in these recent days. India is second largest producer of fruits and vegetables in the world after china, India produced 99.07 million metric tonnes of fruits and 191.77 million metric tonnes of vegetables. On the other hand, many fruits are harvested cannot be fully utilized or processed due to lack of processing techniques and technical know-how. Being highly perishable fruit nature and its short life, it deteriorates at a very faster rate if proper postharvest handling practices and processing techniques are not adopted. Moreover, People in the developing countries like India, they could not afford to diversify their diet with adequate amounts of fruits, vegetables and animal sources of food containing micronutrients hence deficiencies are inevitable also micronutrient deficiencies are unnoticed within the community. For these reasons, fortification is a powerful and cost effective approach to curbs the micronutrient deficiencies. Since India is the largest producer of milk and milk is a staple food for some Indians, it can be fortified with essential nutrients are considered to be reliable source for the hidden hunger. Hence development of fortified milk beverage using fruits and vegetables is not only to treat or prevent the specific nutritional deficiencies but also to promote a general state of well-being in the different population. Conjoint analysis is a multivariate technique used specifically to understand how consumers develop preferences for products or services and to formulate predictions about ingredients levels towards product concepts and it is also called as trade-off analysis. This method is based on the multi-attribute product concepts, i.e. on the premise that consumers evaluate the value or utility of a product by combining the separate amounts of utility provided by each ingredients level. The power of the method is to provide an explanatory model of consumers' preferences, which can then be used to define the product concepts constituting the optimum combination of the attribute levels.

The most important decision in conjoint analysis is selecting the attributes to characterise the fortified beverage. When a large number of combinations $(3$ X 3 X 3 X 3 X $3=243$ ) are presented to sensory panel, the non-response rate (due to fatigue, boredom) becomes very high. Fortunately, the number of cards can be reduced by generating an Orthogonal Array Method using SPSS statistical software. Hence the number of cards created is 16 as shown in Table 3.1. This card is the combination of ingredient levels of beverage. Now, the created card list was given to sensory panel for ranking each card from 1 to16 (1 - highly preferred to 16 - least preferred). With this preference data, conjoint analysis was run.

\section{Materials and Methods}

In this section, materials and methods used in the preparation of Fortified Beverage, Optimization of Ingredients Levels through Conjoint Analysis are discussed.

\section{Material used for the development of Fortified Beverage}

Skim milk, Carrots, Moringa Leaves, Mushrooms, Dates and Sugar were the main 
ingredients in the developed Fortified Beverage. No Chemicals or Synthetic Preservatives were used in the study. The glasswares and instruments utilized were completely sterilized before and after the processes. The analysis of Physico-chemical properties, Nutritional parameters, Microbial quality, Sensory attributes and Storage study of the developed Fortified Beverage followed were Standard methods. Figure.2. shows the flowchart for the product preparation. The following plates show the raw materials utilized for the development of fortified beverage and standardization of the resultant product based on statistical techniques scientifically.

\section{Results and Discussion}

The results of conjoint analysis show the partworth utility values and standard error for attribute levels. Utility refers to a number that represents the value that consumers place on an attribute (the relative worth of the attribute) i.e. higher utility values indicate greater preference. Utilities can be added together to arrive the total utility of any combination. The range of the utility values for each attribute provides a measure of how important the attribute was to the overall preference. Attributes with greater utility ranges play a more significant role than those with smaller ranges. Finally, the measure of the relative importance of each attribute known as an importance score or value is calculated.

\section{Relative importance Utility range for each attribute $=$ sum of utility ranges for all attributes}

The values thus represent percentages and have the property that they sum to 100 . Thus, the conjoint analysis identified the attribute combinations that confer the highest utility to the consumers.

The result of conjoint analysis for ingredient levels of fortified beverage is presented in Table 3.2. Pearson's R and Kendall's tau values are 0.713 and 0.625 respectively indicating a better fit to the data.

Table.1 Card list for Fortified Beverage

\begin{tabular}{|c|c|c|c|c|c|}
\hline CARD ID & CARROT & MUS & MOR & DATES & SW \\
\hline $\mathbf{1}$ & 15 & 3 & 10 & 3 & 1 \\
\hline $\mathbf{2}$ & 5 & 6 & 15 & 1 & 1 \\
\hline $\mathbf{3}$ & 5 & 3 & 5 & 2 & 1 \\
\hline $\mathbf{4}$ & 5 & 6 & 5 & 3 & 3 \\
\hline $\mathbf{5}$ & 5 & 9 & 10 & 1 & 1 \\
\hline $\mathbf{6}$ & 5 & 3 & 5 & 1 & 1 \\
\hline $\mathbf{7}$ & 10 & 3 & 15 & 3 & 1 \\
\hline $\mathbf{8}$ & 5 & 3 & 10 & 2 & 3 \\
\hline $\mathbf{9}$ & 15 & 9 & 15 & 1 & 3 \\
\hline $\mathbf{1 0}$ & 15 & 6 & 5 & 2 & 1 \\
\hline $\mathbf{1 1}$ & 10 & 9 & 5 & 2 & 1 \\
\hline $\mathbf{1 2}$ & 15 & 3 & 5 & 1 & 2 \\
\hline $\mathbf{1 3}$ & 10 & 6 & 10 & 1 & 2 \\
\hline $\mathbf{1 4}$ & 10 & 3 & 5 & 1 & 3 \\
\hline $\mathbf{1 5}$ & 5 & 3 & 15 & 2 & 2 \\
\hline $\mathbf{1 6}$ & 5 & 9 & 5 & 3 & 2 \\
\hline
\end{tabular}


Fig.1 The following are the raw materials utilized for development of Fortified Beverage in their suitable form

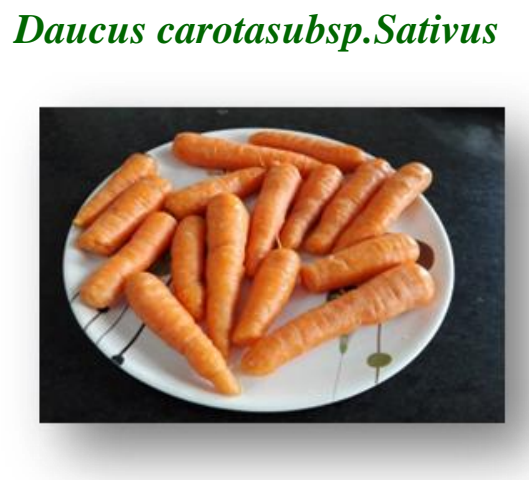

Pleurotus ostreatus

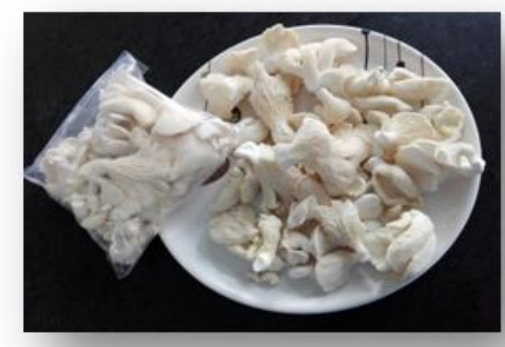

Kappaphycusalvarezii

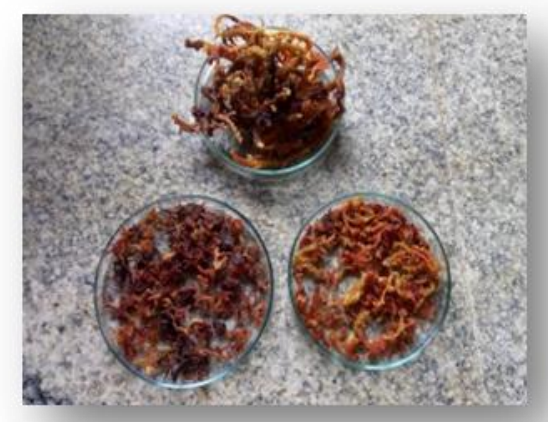

Standardization of Fortified Beverage

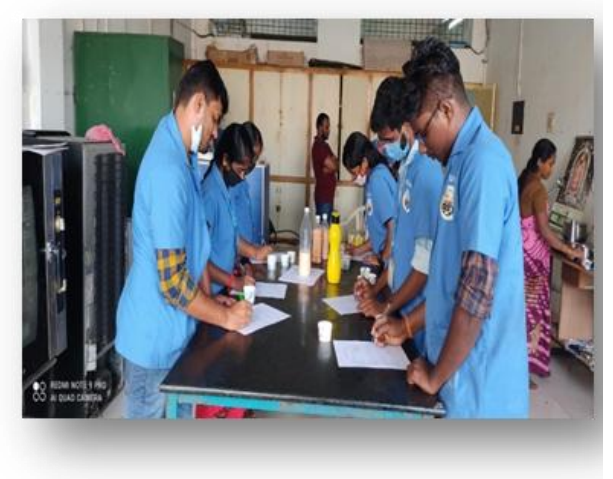

\section{Moringa oleifera}

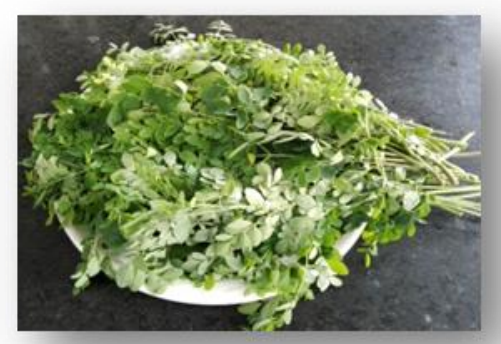

Phoenix dactylifera

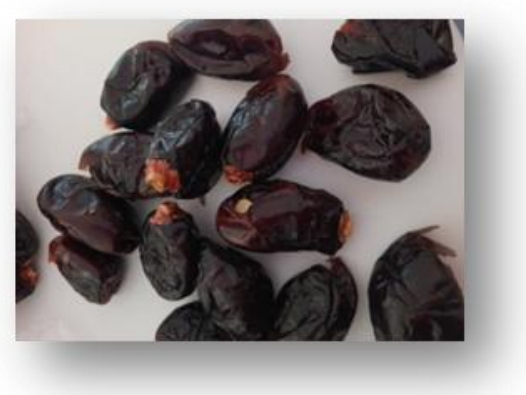

Fortified Beverages

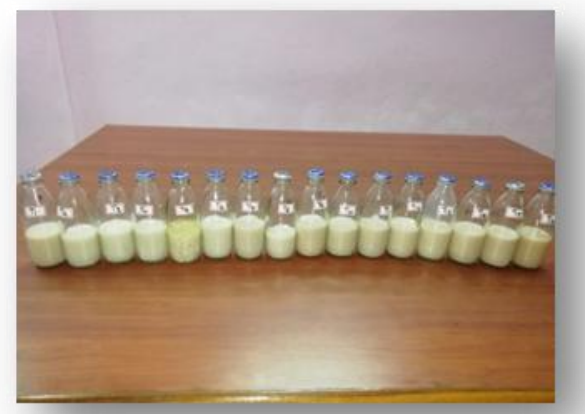

Standardized Fortified Beverage

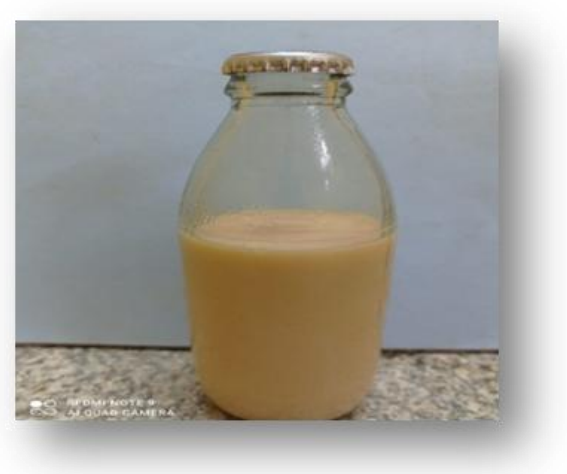


Fig.2 Preparation of Fortified Beverage

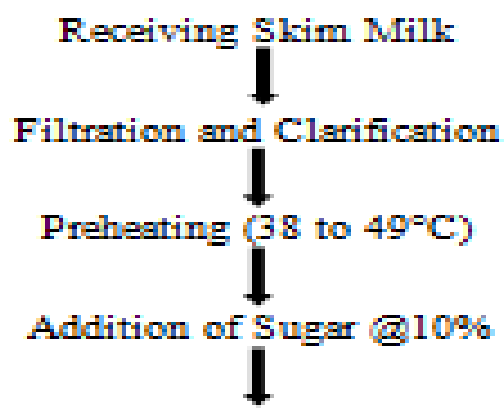

Addition of Fontificants

(Carrot, Mushroom, Moringa, Dates and Seaweed)

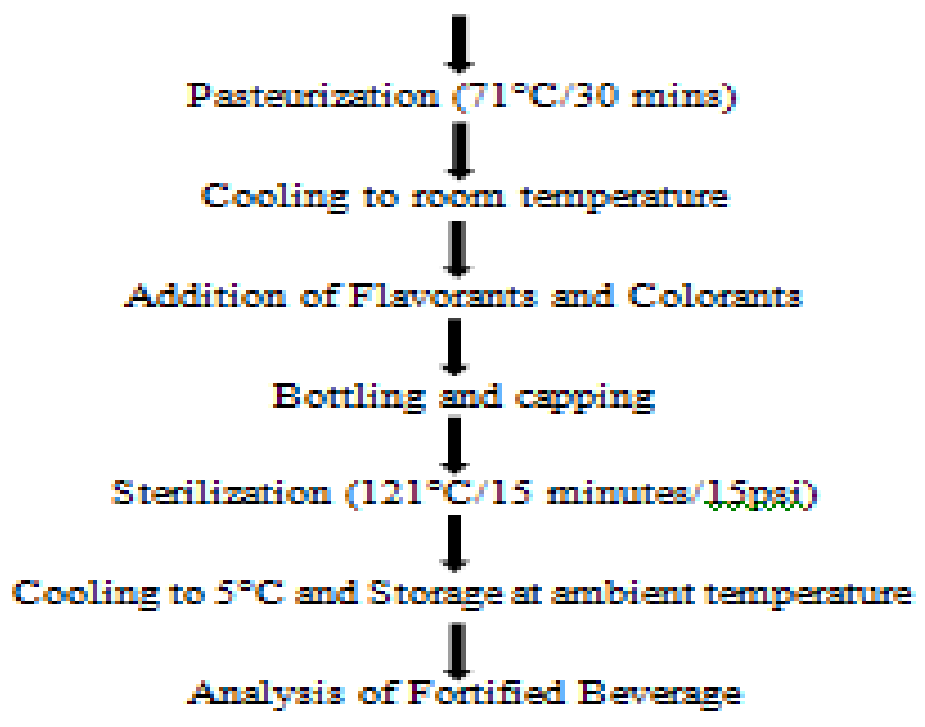

Table.2 Conjoint analysis for quality attributes of Fortified Beverage

\begin{tabular}{|c|c|c|c|}
\hline Attributes & Levels & Utility Estimate & Relative Importance (\%) \\
\hline \multirow[t]{3}{*}{ Carrot } & 5 & -.656 & \multirow[t]{3}{*}{34.06} \\
\hline & 10 & -.742 & \\
\hline & 15 & 1.398 & \\
\hline \multirow[t]{3}{*}{ Mushroom } & 3 & -.696 & \multirow[t]{3}{*}{21.28} \\
\hline & 6 & 1.473 & \\
\hline & 9 & -.777 & \\
\hline \multirow[t]{3}{*}{ Moringa } & 5 & .757 & \multirow[t]{3}{*}{10.93} \\
\hline & 10 & -.725 & \\
\hline & 15 & -.032 & \\
\hline \multirow[t]{3}{*}{ Dates } & 1 & -1.153 & \multirow[t]{3}{*}{23.45} \\
\hline & 2 & 1.622 & \\
\hline & 3 & -.469 & \\
\hline \multirow[t]{3}{*}{ Sea Weed } & 1 & .705 & \multirow[t]{3}{*}{10.18} \\
\hline & 2 & -.130 & \\
\hline & 3 & -.575 & \\
\hline \multicolumn{2}{|c|}{ (Constant) } & 13.304 & \\
\hline \multicolumn{4}{|c|}{ Pearson's $R$ value $=0.713^{* *} ;$ Kendall's tau value $=0.625^{* *}$} \\
\hline \multicolumn{4}{|c|}{$n=15$} \\
\hline
\end{tabular}


The conjoint analysis for selecting the best ingredient levels of ideal fortified beverage found that it should have the following attributes combination: Carrot -15 per cent, Mushroom - 6 Per cent, Moringa - 5 per cent, Dates -2 per cent and Sea Weed -1 per cent.

\section{Acknowledgement}

Foremost immeasurable debt of gratitude goes to God; we could not have completed this work without the help of god the Almighty. The authors would like to acknowledge College of Food and Dairy Technology, Tamil Nadu Veterinary and Animal Sciences University, Chennai for their support and encouragement throughout the research work. Authors also wish to place on record their heartfelt thanks to each and every one who had their part in this research work.

\section{Funding Source}

College of Food and Dairy Technology, Tamil Nadu Veterinary and Animal Sciences University, Koduvalli, Chennai - 600052.

\section{References}

\section{How to cite this article:}

Navarasam, R., Ayyavoo Preamnath Manoharan, V. Appa Rao, T. R. Pugazhenthi and Serma Saravana Pandian, A. 2021. Conjoint Analysis for Selecting the Ingredients Levels of Fortified Beverage. Int.J.Curr.Microbiol.App.Sci. 10(09): 146-151.

doi: https://doi.org/10.20546/ijcmas.2021.1009.017
Annunziata, A. and R. Vecchio (2013). Consumer perception of functional foods: A conjoint analysis with probiotics. Food Quality and Preference, 28: 348-335.

Bech-Larsen, T. and K. G. Grunert (2003).The perceived healthiness of functional foods- A conjoint study of Danish, Finnish and American consumers' perception of functional foods.Appetite,40: 9-14.

Grunert, K. G., T. Bech-Larsen and L. Bredahl (2000).Three issues in consumer quality perception and acceptance of dairy products. International Dairy Journal10: 575 - 584 .

Hoppert, K., R. Mai, S. Zahn, S. Hoffmann and H. Rohm (2012).Integrating sensory evaluation in adaptive conjoint analysis to elaborate the conflicting influence of intrinsic and extrinsic attributes on food choice.Appetite,59: $949-955$.

Murphy, M., Cowan, C., H. Meehan and S. O'Reilly (2004). A conjoint analysis of Irish consumer preferences for farmhouse cheese. British Food Journal, 106(4): 288 - 300. 